\title{
Investigation of Thermal Performance for Atria: a Method Overview
}

\author{
Leila Moosavi ${ }^{1, a}$, Norafida Ghafar ${ }^{1}$ and Norhayati Mahyuddin ${ }^{1}$ \\ ${ }^{1}$ Center for Urban Conservation and Tropical Architecture, Faculty of Built Environment, University of Malaya, Malaysia
}

\begin{abstract}
The importance of low energy design in large buildings has encouraged researchers to implement different methods for predicting a building's thermal performance. Atria, as energy efficient features, have been implemented to improve the indoor thermal environment in large modern buildings. Though widely implemented, the thorough study of atrium performance is restricted due to its large size, complex thermodynamic behavior and the inaccuracies and limitations of available prediction tools. This study reviews the most common research tools implemented in previous researches on atria thermal performance, to explore the advantages and limitation of different methods for future studies. The methods reviewed are analytical, experimental, computer modelling and a combination of any or all of these methods. The findings showed that CFD (computational fluid dynamic) models are the most popular tools of recent due to their higher accuracy, capabilities and user-friendly modification. Although the experimental methods were reliable for predicting atria thermal and ventilation performance, they have mostly been used to provide data for validation of CFD models. Furthermore, coupling CFD with other experimental models could increase the reliability and accuracy of the models and provide a more comprehensive analysis.
\end{abstract}

\section{Introduction}

Different studies about atrium thermal performance discuss the importance of implementing low energy design for new large buildings to reduce energy consumption. The atrium is a large open space with glazed roof or walls located within a building creating a common space for interconnecting adjacent stories. Atria also have potential environmental advantages such as providing natural daylight and natural ventilation for its adjacent spaces.

The complexity of the nature of air flow in an atrium can cause difficulty in experimental investigations and consequently impose significant challenges on computational modelling for flow prediction [2]. On the other hand, it is difficult to rely on the results of previous studies alone to generalize those achievements for other atrium types with different conditions [3]. Therefore, each atrium models require specific experimental or computational studies to fulfill the concerns of the accuracy in predicting results.

Different types of methods have been implemented in previous studies for the investigation thermal performance of various atrium models. These methods take into consideration the accuracy and capability to provide detailed information, cost and user-friendliness. Therefore, a review of the application of the methods in previous atrium studies and a highlight of the limitation and advantages of those methods is influential for choosing the appropriate method for further studies.

\footnotetext{
${ }^{1}$ a Corresponding author: leilamoosavi@yahoo.com
}

This study starts with a review of the main methods implemented in the previous studies regarding their advantages and disadvantages. Next, the implemented method are investigated based on the purpose of the studies. Finally, in order to find the most appropriate methods for certain atrium studies, all the mentioned methods are compared and discussed accordingly. The scope of this study is limited to previous researches on atrium which evaluated indoor thermal and ventilation conditions.

\section{Main methods implemented for atria}

This section reviews the most common research methodologies implemented in previous researches. A thorough study of atrium performance is restricted due to inaccuracies and limitations of the available prediction tools [4] and controlled experiments. In general, there are four common methods often implemented in studies of naturally ventilated atria which include analytical model, real building measurement (field study/ experimental study), small scale model simulation studies (experimental study) using computer modelling and a combination of any or all of the aforementioned methods.

\subsection{Analytical model}

The analytical models are probably the oldest method for predicting atrium ventilation performance. This method is still widely used today for its simplicity, richness in physical meaning and little requirement in computing 
resources, although it may not be accurate for atria with complicated ventilation and the results may not be informative. In cases with simple atrium models, although the final equations obtained for one atrium model may not be used for another without modifications, the methodology and approximations can be similar for different models [5].

Assadi, Dalir [6] implemented the analytical model to evaluate the energy efficiency of an atrium building with buoyancy-driven natural ventilation by testing design parameters such as atrium dimension and glass height. Lin and Linden [7] used theoretical analysis coupled with the experimental analysis using a salt solution to investigate the transient behavior of stratification through the atrium with buoyancy effect. Ji and Cook [8] also implemented a simple analytical model to examine the thermal performance of buoyancy-driven natural ventilation atrium with multi-storey building and a solar chimney by focusing on the impact of the height of the building and opening size. However, discrepancies were observed between CFD results and analytical model.

\subsection{Measurement and monitoring of real atria}

Measurement and monitoring is an influential method implemented for evaluating atrium thermal performance. Actual building measurements or field experiments are carried out on site using one or several measuring equipment and apparatus to evaluate the performance of existing buildings by conducting scientific data collection $[5,9-12]$. It can also be done via personal observation or user response study to assess the monitored building as a case study. The atrium's internal environment is not stable and changes daily in response to the ambient conditions; therefore, an on-site monitoring of the atrium building is effective to explore the impact of the ambient conditions on the indoor thermal environment of the atrium. Another advantage of conducting field studies for atrium building is that it provides appropriate data for validation of the simulation software implemented in the atrium model.

Despite all the advantages, there are several disadvantages in using this method for atrium investigation. Compared to other building types, the measurement of atria buildings is more difficult due to the largeness of atrium and complexity of thermal and airflow behaviors in atrium. Therefore, to cover all the areas of the atrium while monitoring, a large number of equipment is required. On the other hand, monitoring and measuring atrium buildings need plenty of time to ensure that reliable data is used in the analysis stage. However, even with providing the aforementioned requirements, there is still possibility of human errors occurring during the measurement period, in setting and handling measurement equipment. Another limitation of situ measurement as compared to laboratory experiments is the difficulty in changing boundary condition to test design modification.

In most of the cases, only changing the opening position is possible. Table 1 compares two main measurement techniques, the investigated parameters and implemented devices from previous studies about atria.

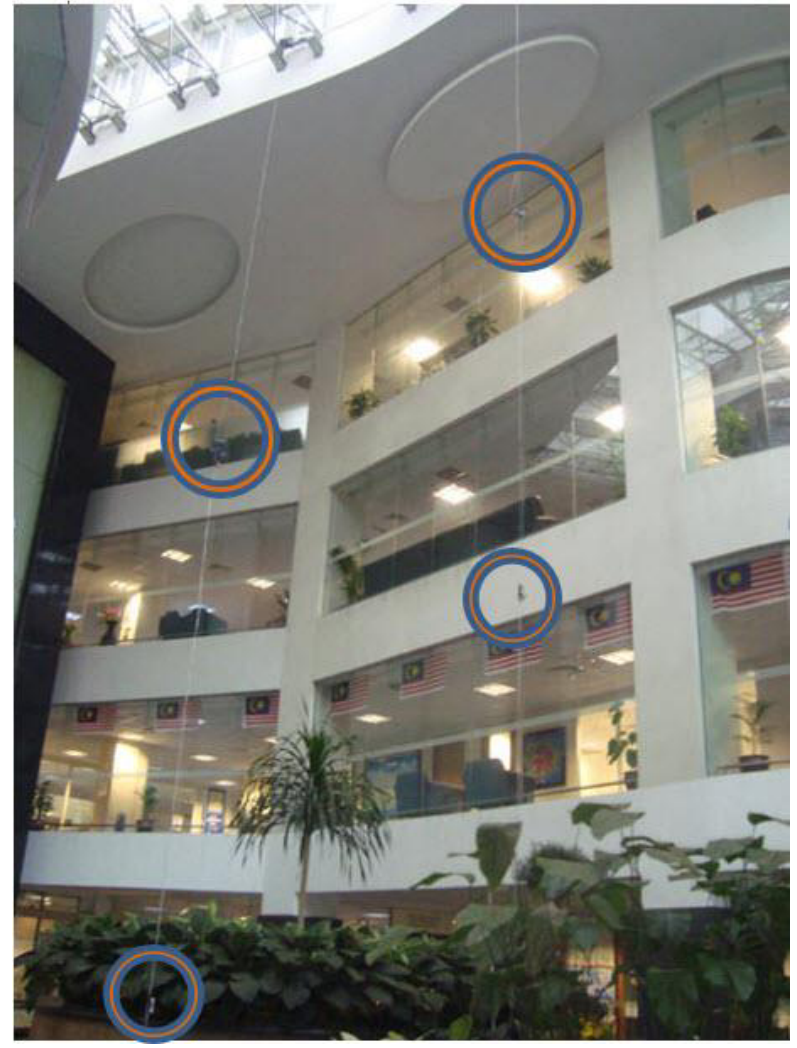

Figure 1. Monitoring and measurement of an office building in the tropics [13].

Few studies have implemented situ measurement to investigate atria thermal performance [14-17] (Figure 1). Abdullah and Wang [18] carried out site measurement to evaluate the thermal performance of a large multi-level atrium building and implemented the results to validate used TAS program. Pfafferott, Herkel [19] implemented a new method for analysis to deal with short-term and longterm measurement and atrium building simulation using ESP-r. Tanaka, Okumiya [15] undertook field measurement to investigate the cooling loads of atrium building with a double-glaze external wall.

\subsection{Scale model experiments}

Implementing scale model instead of a field study, is beneficial in terms of lower cost and practicality especially for high rise buildings. It is also used commonly to visualize airflow patterns and temperature rate in and around atrium buildings and investigating opposing and assisting effects of wind on buoyancy with the aid of a wind or water tunnel [20] (Table 1). This model is capable of predicting the actual building conditions with a reasonable degree of accuracy [21-23]. The highest similarity of air mean velocity fields in the scale model is obtained when airflow in both scale model and real space 
are fully turbulent [24]. Three types of scale model experiments used for investigating thermal and ventilation conditions in atria buildings are wind tunnel model, salt bath model and fine hydrogen bubbles. Wind tunnel scale models are also used to determine wind pressure coefficients, to be used for calculating the ventilation rates indirectly [25]. While, the salt-bath methods is mostly implemented to visualize the atrium ventilation with thermal buoyancy [23].

Ding, Hasemi [30] carried out reduced scale model experiment to examine the stack effect performance in an eight-storey office atrium building in Tokyo. Bensalem [29] used wind tunnel model to evaluate the thermal performance of atrium with wind-driven natural ventilation. Liu, Lin [31] used salt bath model and Walker, Tana [1] used reduced scale method. Both were coupled with CFD for investigating thermal performance of atrium building with buoyancy-driven natural ventilation (figure 2). Holford and Hunt [23] implemented small-scale and theoretical models to investigate the flow enhancement in the atrium using heat source and solar heat gain. According to the results, the experimental results of the scale models were in agreement with other CFD or analytical results.

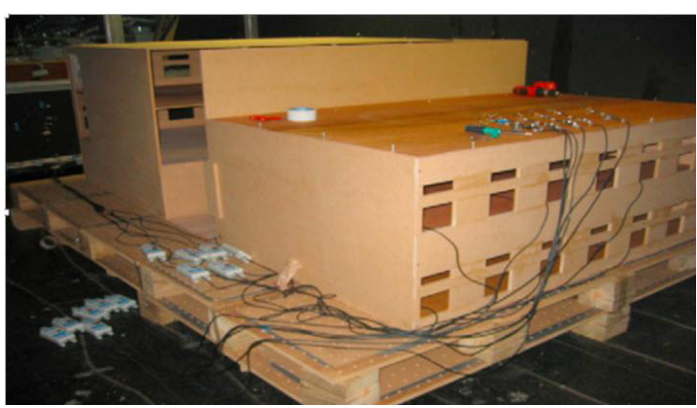

Figure 2. The scaled air model in the test chamber [1].

\subsection{Computational modelling}

Computational modeling has been used increasingly to simulate airflow patterns through atria buildings and predict atrium airflow and thermal field. Generally, the three most popular computational methods for modelling airflow in atria are multi-zone, zonal and computational fluid dynamics (CFD) models. The multi-zone model is

Table 1: Typical measurement techniques for thermal evaluation and ventilation performance of atria

\begin{tabular}{|c|c|c|c|c|}
\hline & Problem & Measurable variable & Measurement devices & References \\
\hline \multirow[b]{3}{*}{$\begin{array}{c}\text { Building } \\
\text { measureme }\end{array}$} & Overheating & Temperature & $\begin{array}{l}\text { Thermal Comfort } \\
\text { Meter } \\
\text { thermocouple }\end{array}$ & {$[14]$} \\
\hline & Stratification & $\begin{array}{c}\text { Mean radiant } \\
\text { temperature, } \\
\text { Air temperature and wall } \\
\text { surface temperature. }\end{array}$ & $\begin{array}{l}\text { Thermal Radiometer } \\
\text { Thermocouple }\end{array}$ & {$[26]$} \\
\hline & $\begin{array}{c}\text { Solar heat gain, } \\
\text { Glare }\end{array}$ & $\begin{array}{c}\text { Radiant temperature, } \\
\text { Air temperature, } \\
\text { Air velocity }\end{array}$ & $\begin{array}{c}\text { Thermal Radiometer. } \\
\text { Thermocouples } \\
\text { anemometer }\end{array}$ & {$[15]$} \\
\hline \multirow{4}{*}{ Small scale } & $\begin{array}{l}\text { Solar heat } \\
\text { gain, } \\
\text { Glare }\end{array}$ & $\begin{array}{c}\text { Daylight factor, } \\
\text { Temperature, } \\
\text { Airflow } \\
\end{array}$ & $\begin{array}{c}\text { Sensitive } \\
\text { photometers }\end{array}$ & [27] \\
\hline & Overheating & $\begin{array}{l}\text { Temperature, } \\
\text { Airflow velocity, }\end{array}$ & $\begin{array}{l}\text { Thermocouple, } \\
\text { Anemometer } \\
\text {, flow hood, } \\
\text { Smoke pencils }\end{array}$ & [1] \\
\hline & Stratification & $\begin{array}{l}\text { Displacement } \\
\text { ventilation }\end{array}$ & $\begin{array}{c}\text { Salt solutions, forced } \\
\text { chamber, Unforced } \\
\text { chamber/ }\end{array}$ & {$[7,28]$} \\
\hline & $\begin{array}{l}\text { Ventilation } \\
\text { control }\end{array}$ & $\begin{array}{l}\text { Airflow rate, } \\
\text { Airflow pattern }\end{array}$ & Wind tunnel test & [29] \\
\hline
\end{tabular}


assumption in these models. In this regards, zonal models have been employed to compensate for the problem of predicting air temperature distributions in the multi-zone model. However, the zonal model has a limitation in predicting airflow pattern and is insufficient for driving flows with high momentum. Tan and Glicksman [32] validated a developed multi-zone model program, MMPN, for naturally ventilated atrium buildings using CFD method. Their results showed that by implementing the results of the multi-zone model in CFD model, CFD can simulate and provide accurate detailed information for the atrium and also save a significant amount of computation time.

Computational fluid dynamics (CFD) is a powerful tool that has been improved remarkably in recent years for the design of indoor climate control. Compared to the zonal models, which are macroscopic, the CFD models, as microscopic models, have extremely small cells to control the macro-volumes. Although in atria, due to the large size of space and also the complicated behavior of flow field, simulating the flow field using the CFD model face several difficulties, it still is a unique method to make the accurate and detailed analysis possible [33]. Many researchers employed CFD models to predict indoor thermal environment of the atria buildings and their results proved that the CFD model is appropriate for providing the detail thermal and ventilation performance of atrium [34, 35] [36] [37]. Kondo and Niwa [38] carried out a numerical study on the atrium thermal performance using $\mathrm{k}-\varepsilon$ turbulence model. C.A. Rundle, M.F. Lightstone [16] and Ding, Hasemi [30] Hussain and Oosthuizen [39] used CFD method to study on the atria model in which turbulent natural convection coupled with radiative heat transfer (figure 3).

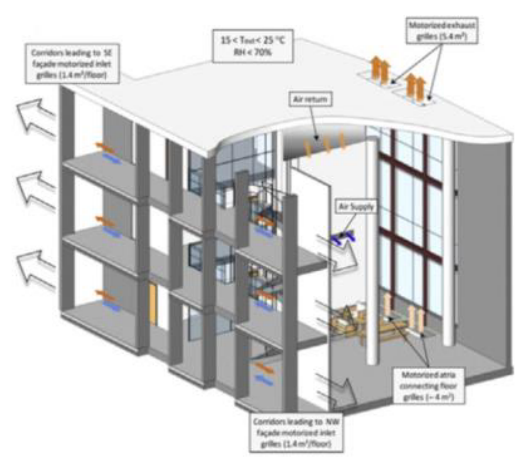

Figure 3: A mode of the atrium and adjacent spaces in the engineering building of Concordia university, Canada, hybrid ventilation concept [17].

\section{The purpose of using methods in atria studies}

According to the literature, the purposes of studies about atria are mainly to investigate atrium indoor thermal and ventilation conditions or validate the computational model implemented. The following section discusses these two scopes with some examples.

\subsection{Investigating atrium thermal performance}

Among different studies about atrium thermal performance, a limited number have investigated atrium real indoor thermal condition using field measurement and monitoring [18] [13, 15, 19]. While, a large number of studies examined different design parameters to improve atrium thermal performance such as the impact of opening design $[1,23,30,40,41]$ or atrium shape $[6,42]$ or atrium roof form [43] (figure 4). Lin and Linden [7], Holford and Hunt [23], and Wang, Huang [26] separately used theoretical and experimental analyses to evaluate the thermal performances of atria with different opening aspects (size, location, and status). Furthermore, there are also studies on the evaluation of the performance of different implemented strategies in atrium buildings such as solar assisted natural ventilation [44] [15, 45], night ventilation performance in atrium [19] [46] [47] [17] [17] or wind-induce strategy [48] [49] [28, 50] using CFD and experimental methods. More details about the aforementioned studies are available in [3].

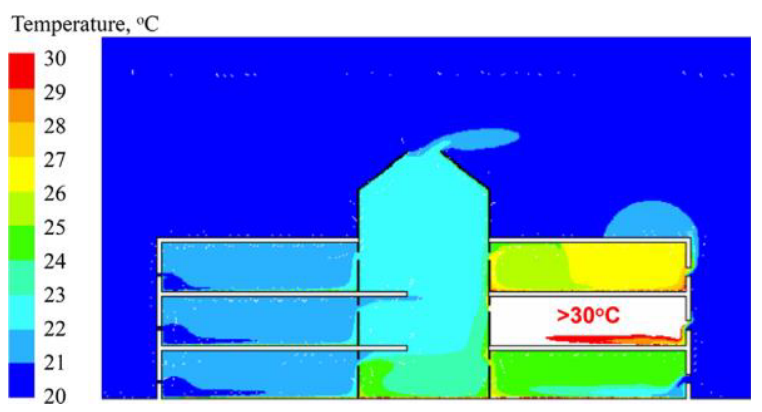

Figure 4. Predicted air temperature in the naturally ventilated atrium building with wind- ward openings reduced to $0.1 \mathrm{~m}$ [20].

\subsection{Validation of computational model}

Since the nature of airflow behavior and heat transfer in atrium buildings is complicated and hard to predict, many studies have carried out experimental and numerical studies for validating the accuracy of the numerical simulation tools for atria by comparing the predicted results with the experimental results [31, 49, 51-53]. In all the studies mentioned above, there was a good agreement between numerical and experimental results. Some of the researchers evaluated the accuracy of the CFD model implemented [31]. Hussain and Oosthuizen [52] compared different RANS turbulence models with radiation model for atrium with hybrid ventilation. Furthermore, the number of researches are limited to testing different boundary conditions, as the sensitivity test, for more accurate results. For example, Gan [54] study indicates that a more accurate simulation of natural ventilation is achieved using a larger computational domain in enclosures with large openings for the naturally ventilated atrium. 
Table 2: Advantages and disadvantages of each modelling technique

\begin{tabular}{|c|c|c|c|}
\hline Technique & Description & Advantages & Disadvantage \\
\hline $\begin{array}{l}\text { Simplified } \\
\text { theoretical } \\
\text { models }\end{array}$ & $\begin{array}{c}\text { Simple (one-equation) } \\
\text { method for calculating } \\
\text { approximate airflow rates in } \\
\text { a single space }\end{array}$ & Quick, easy and cheap & $\begin{array}{l}\text { Less accuracy, No information } \\
\text { on airflow within space }\end{array}$ \\
\hline $\begin{array}{c}\text { On-site } \\
\text { measurement }\end{array}$ & $\begin{array}{l}\text { Experimental technique } \\
\text { Measuring the real } \\
\text { conditions }\end{array}$ & $\begin{array}{l}\text { Many physical problems in } \\
\text { wind engineering and } \\
\text { building physics, such as } \\
\text { wind-driven rain on } \\
\text { buildings and heat and } \\
\text { moisture transfer in porous } \\
\text { building components require } \\
\text { on-site measurements }\end{array}$ & $\begin{array}{l}\text { Not controllable, the numbers of } \\
\text { variables are constrained, Not } \\
\text { predictable, There may be } \\
\text { unexpected disturbances during } \\
\text { an experimental measurement. } \\
\text { There are also administrative } \\
\text { limitations }\end{array}$ \\
\hline $\begin{array}{l}\text { Wind tunnel } \\
\text { testing }\end{array}$ & $\begin{array}{l}\text { Experimental technique in } \\
\text { which models of buildings } \\
\text { and their surroundings are } \\
\text { subjected to varying (and } \\
\text { controlled) wind speeds. }\end{array}$ & $\begin{array}{l}\text { Ideally suited for modelling } \\
\text { external airflows. Flow } \\
\text { visualization possible. }\end{array}$ & $\begin{array}{l}\text { Expensive and time consuming. } \\
\text { Not possible to model internal } \\
\text { flows. }\end{array}$ \\
\hline $\begin{array}{l}\text { Salt-Bath } \\
\text { modelling }\end{array}$ & $\begin{array}{l}\text { Experimental technique in } \\
\text { which Perspex models of } \\
\text { buildings are submerged in } \\
\text { water and brine injected to } \\
\text { represent sources of heat. }\end{array}$ & $\begin{array}{l}\text { Visually easy to appreciate, } \\
\text { Qualitative flow pattern } \\
\text { within space can be realized } \\
\text { and easily photographed, } \\
\text { Possible to measure specific } \\
\text { parameters. }\end{array}$ & $\begin{array}{l}\text { Expensive to construct accurate } \\
\text { models, time-consuming to } \\
\text { make geometric changes, Not } \\
\text { possible to measure variables at } \\
\text { arbitrary positions without } \\
\text { intrusive apparatus, practical } \\
\text { experience required, Few } \\
\text { equipped laboratories, no heat } \\
\text { exchange with structure. }\end{array}$ \\
\hline $\begin{array}{l}\text { Multi-zone } \\
\text { models }\end{array}$ & $\begin{array}{l}\text { A simple technique for } \\
\text { predicting air exchange rates } \\
\text { and airflow distributions in } \\
\text { buildings, calculate } \\
\text { ventilation efficiency, } \\
\text { energy demand, pollutant } \\
\text { transport, and smoke } \\
\text { control. }\end{array}$ & $\begin{array}{l}\text { User-friendly, } \\
\text { straightforward internal } \\
\text { representation and } \\
\text { calculation procedure. The } \\
\text { prediction of overall flow } \\
\text { through the building. }\end{array}$ & $\begin{array}{l}\text { cannot represent detailed } \\
\text { temperature and airflow } \\
\text { distributions within a single } \\
\text { space, due to its 'well-mixed' } \\
\text { assumption }\end{array}$ \\
\hline Zonal models & $\begin{array}{c}\text { A simple technique for } \\
\text { calculating airflow rates } \\
\text { between adjacent zones of a } \\
\text { multi-zone space. }\end{array}$ & $\begin{array}{l}\text { Quick, easy and cheap. } \\
\text { More accurate than } \\
\text { simplified theoretical } \\
\text { models. }\end{array}$ & $\begin{array}{c}\text { Still no information on airflow } \\
\text { within spaces. Some training } \\
\text { required }\end{array}$ \\
\hline $\begin{array}{l}\text { Computational } \\
\text { fluid dynamics }\end{array}$ & $\begin{array}{l}\text { Computational technique } \\
\text { which primarily solves } \\
\text { conservation equations of } \\
\text { mass, Momentum and } \\
\text { energy to find velocities, } \\
\text { temperatures and pressure } \\
\text { throughout the whole } \\
\text { domain }\end{array}$ & $\begin{array}{l}\text { Potentially very accurate, } \\
\text { Able to predict spatial } \\
\text { information giving values } \\
\text { for variables throughout the } \\
\text { entire flow domain, easy to } \\
\text { investigate changes in } \\
\text { geometry and operating } \\
\text { conditions, Additional } \\
\text { physical models (e.g. } \\
\text { radiation models and } \\
\text { contaminant dispersion) can } \\
\text { be added with relative ease. }\end{array}$ & $\begin{array}{l}\text { Experience required achieving } \\
\text { optimum performance from the } \\
\text { code. Very computationally } \\
\text { intensive, detailed simulations } \\
\text { of entire buildings or long } \\
\text { transient simulations are } \\
\text { currently prohibitive, some } \\
\text { validation/development is still } \\
\text { required, particularly in the area } \\
\text { of turbulence modelling and } \\
\text { buoyancy-driven flows. }\end{array}$ \\
\hline
\end{tabular}




\section{Discussion:}

Table 2 compares the advantages and disadvantages of different methods implemented in atria studies. According to the literature, it seems that the small-scale and full-scale experimental models were mostly implemented to generate data for validating the numerical models of atrium $[55,56]$. Compared with small scale models, zonal modelling and CFD modelling of a 3D full-scale building are more effective design tools in predicting thermal and ventilation performance of the entire atrium building. Among the different atrium models reviewed, the CFD models (of a 3D full-scale building) were the most popular and contributed to about 70 percent of the literature. The application of CFD for atrium models were mostly to investigate temperature distributions, airflow rate and pattern and thermal stratification respectively since predicting these variables with detail throughout the atrium space were difficult using other models.

The review showed that, in general, to have a better understanding of indoor thermal conditions of atrium buildings, such as temperature distribution and airflow rate, situ measurement have been used while, for testing different design parameters and their impact on the thermal performance of atria, CFD method was a common method implemented. Furthermore, in order to evaluate airflow pattern and thermal stratification throughout the atrium and adjacent spaces, a combination of both experimental and numerical simulation methods was used.

\subsection{Combination of methods}

Due to the lack of powerful methods for producing complete and accurate analysis, particularly for energyrelated and indoor air quality atrium research, some researchers attempted to combine the different methods mentioned in section 2 [5]. Employing combined methods assists the researchers to fill the gap in any shortcomings of a particular method, validates the results and correlates the findings [57]. In another study on atrium design, Navvab [58] discussed the combination of methods as a back-and-forth process which starts by testing the atrium design implementing a scale model and proceeds to developing computer models for the parametric studies. Then, by going back to the scale model, the design can be refined. The combination of methods, such as the multizone models with CFD, can save a significant amount of computation time [59].

Combined methods have been increasingly employed in different research studies. Some researchers applied one model to produce some primary input data, as the boundary condition, for the next model in order to increase the accuracy of the atrium modelling results [60]. For example, Tan and Glicksman [32] integrated a multi-zone model (MMPN) and computational fluid dynamics (CFD) to modelling naturally ventilated atrium. They transferred velocity and pressure data from a multi-zone model program to CFD as boundary conditions. Other researchers use the coupled models for validation the computational model by comparing the experimental results with the simulation results (as discussed in section 3.2). However, most of the time, there are partial differences between the two modelling results since none of the modelling techniques are perfect.

Although employing different methods resulted in a better understanding of the complex nature of the problem and provided comprehensive and more accurate results, it also has limitations. For instance, it is time-consuming and costly due to different types of equipment and various techniques for each method that is continuously involving. However, according to the literature, for a well-resourced program, implementing a combined method is recommended.

\section{Conclusion}

This paper reviewed various methods implemented for investigating atrium indoor thermal and ventilation conditions. As mentioned, the most common methods cited in the literature for atrium studies are analytical, experimental (situ measurement and scale model) and computational modelling (multi-zone, zonal, and CFD models). The methods were compared and the advantages and limitations of each method was discussed. Among different methods implemented, CFD is the most accurate method to predict indoor temperature distribution, airflow behavior and rate for the atrium in details.

Based on the literature, to ensure the accuracy of the predicted results, more comparison between CFD results and experimental results are required. It is also helpful for the validation of the software implemented and examining the turbulence models. In most cases reviewed, for the study about atrium design parameters, CFD modelling, for investigating the impact of the ambient condition on atrium indoor thermal condition, situ measurement and for modelling indoor airflow pattern, the combination of experimental study and CFD modeling were implemented.

\section{References}

1. Walker, C., G. Tana, and L. Glicksman, Reducedscale building model and numerical investigations to buoyancy-driven natural ventilation. Energy and Buildings, 2011(43): p. 2404-2413.

2. Awbi, H.B., Ventilation of buildings. 2003: Taylor \& Francis.

3. Moosavi, L., et al., Thermal performance of atria: An overview of natural ventilation effective designs. Renewable and Sustainable Energy Reviews, 2014. 34: p. 654-670.

4. Laouadi, A., M. Atif, and A. Galasiu, Towards developing skylight design tools for thermal and energy performance of atriums in cold climates. Building and environment, 2002. 37(12): p. 1289-1316.

5. Chen, Q., Ventilation performance prediction for buildings: A method overview and recent applications. Building and environment, 2009. 44(4): p. 848-858.

6. Assadi, M.K., F. Dalir, and A.A. Hamidi, Analytical model of atrium for heating and 
ventilating an institutional building naturally. Energy and Buildings, 2011. 43(10): p. 25952601.

7. Lin, Y. and P. Linden, Buoyancy-driven ventilation between two chambers. Journal of Fluid Mechanics, 2002. 463(1): p. 293-312.

8. Ji, Y. and M. Cook. Atrium-assisted natural ventilation of multi-storey buildings. in Proceedings of the 10th International Conference on Indoor Air Quality and Climate. 2005. Beijing, China.

9. Baker, N., The atrium environment. Building TechicalFile, 1988. No.21: p. 39-48.

10. Kainlauri, E., G. Lehman, and M. Vilmain. Comparative studies of five atriums on the effects of orientation, exposure and design on daylighting, temperature, and stratification of air. in Proceedings of the Biennial Congress of the International Solar Energy Society. 1991.

11. Jones, J., M. Luther, and M. Nawab. $A$ Comparative Analysis for Two Geometrically Different Atria. in Solar World Congress, Proceedings of the Biennial Congress of the International Solar Energy Society, Denver, Colorado, USA. 1991.

12. Abdullah, A. and F. Wang. Effect of Water Spray and Blinds on Indoor Thermal Environment in an Atrium in Tropical Climate. in Proceedings of the Asean Postgraduate Seminar in Built Environment, Faculty of Built Environment. 2005.

13. Moosavi, L., N. Mahyuddin, and N. Ab Ghafar, Atrium Cooling Performance in a Low Energy Office Building in the Tropics, A Field Study. Building and Environment, 2015.

14. Abdullah, A.H., et al., Field study on indoor thermal environment in an atrium in tropical climates. Building and environment, 2009. 44(2): p. 431-436.

15. Tanaka, H., et al., Thermal characteristics of a double-glazed external wall system with roll screen in cooling season. Building and environment, 2009. 44(7): p. 1509-1516.

16. C.A. Rundle, et al., Validation of computational fluid dynamics simulations for atria geometries,. Buildings and Environment, 2011. 46: p. 13431353.

17. Karavaa, P., et al., Experimental study of the thermal performance of a large institutional building with mixed-mode cooling and hybrid ventilation. Building and Environment, 2012. 57: p. 313-326.

18. Abdullah, A.H. and F. Wang, Modelling thermal stratification in atrium using TAS program and verification of prediction results. International Journal of Integrated Engineering, 2011. 1(2): p. 79-93.

19. Pfafferott, J., S. Herkel, and M. Wambsgan 3 , Design, monitoring and evaluation of a low energy office building with passive cooling by night ventilation. Energy and Buildings, 2004. 36(5): p. 455-465.

20. Gan, G., Interaction between wind and buoyancy effects in natural ventilation of buildings. Open Construction and Building Technology Journal, 2010. 4: p. 134-145.

21. Iyer-Raniga, U., Daylighting in atrium spaces. Architectural Science Review, 1994. 37(4): p. 195-208.

22. Li, Y., Buoyancy-driven natural ventilation in a thermally stratified one-zone building. Building and environment, 2000. 35(3): p. 207-214.

23. Holford, J.M. and G.R. Hunt, Fundamental atrium design for natural ventilation. Building and environment, 2003. 38(3): p. 409-426.

24. Abdullah, A.H., A Study on Thermal Environmental Performance in Atria in the Tropics with Special Reference to Malaysia, in Built Envirinment. 2007, Heriot-Watt University: Heriot-Watt University.

25. Carey, P. and D. Etheridge, Direct wind tunnel modelling of natural ventilation for design purposes. Building Services Engineering Research and Technology, 1999. 20(3): p. 131142 .

26. Wang, X., C. Huang, and W. Cao, Mathematical modeling and experimental study on vertical temperature distribution of hybrid ventilation in an atrium building. Energy and Buildings, 2009. 41(9): p. 907-914.

27. Fuziah, S., Z.A. Azni, and A.R. Shuzlina, Daylight modelling and thermal performance of atrium of new MECM building at Putrajaya. IEM Journal 2004. 65(3\&4): p. 1-42.

28. Woods, A.W., S. Fitzgerald, and S. Livermore, $A$ comparison of winter pre-heating requirements for natural displacement and natural mixing ventilation. Energy and Buildings, 2009. 41(12): p. 1306-1312.

29. Bensalem, R., Wind driven natural ventilation in courtyard and atrium-type buildings. 1991, University of Sheffield.

30. Ding, W., Y. Hasemi, and T. Yamada, Natural ventilation performance of a double-skin façade with a solar chimney. Energy and Buildings, 2005. 37(4): p. 411-418.

31. Liu, P.-C., H.-T. Lin, and J.-H. Chou, Evaluation of buoyancy-driven ventilation in atrium buildings using computational fluid dynamics and reduced-scale air model. Building and environment, 2009. 44(9): p. 1970-1979.

32. Tan, G. and L.R. Glicksman, Application of integrating multi-zone model with CFD simulation to natural ventilation prediction. Energy and Buildings, 2005. 37(10): p. 10491057.

33. Liddament, M.W. and A. Infiltration, A review of ventilation efficiency. 1993: Air Infiltration and Ventilation Centre. 
34. Oosthuizen, P. and M. Lightstone. Numerical analysis of the flow and temperature distributions in an atrium. in Proceedings of 2009 international conference on computational methods for energy engineering and environment: ICCM3E, 20e22 November. 2009.

35. Hangen, H., et al., Case study: numerical simulations for comfort assessment and optimization of the ventilation design for complex atriums,. Journal of Wind Engineering and Industrial Aerodynamics, 2001(89): p. 10311045.

36. Schild PG, Tjelflaat PO, and Aiulfi D, Guidelines for CFD modelling of atria. ;101:1311e32. 1995: ASHRAE Transactions.

37. M. J. Cook, Y. Ji, and G.R. Hun, CFD modeling of natural ventilation: combined wind and buoyancy forces. International Journal of Ventilation. 2003. 1: p. 169-180.

38. Kondo, Y. and H. Niwa. Numerical study of an atrium by means of a macroscopic model and $k-\varepsilon$ turbulence model. in Proceedings of the Room Air Convection and Ventilation Effectiveness. 1992. Tokyo.

39. Hussain, S. and P.H. Oosthuizen. A Numerical Study of the Effect of Thermal Mass on the Transient Thermal Performance of a Simple Three Storied Atrium Building. in ASME 2012 Heat Transfer Summer Conference collocated with the ASME 2012 Fluids Engineering Division Summer Meeting and the ASME 2012 10th International Conference on Nanochannels, Microchannels, and Minichannels. 2012. American Society of Mechanical Engineers.

40. Ji, Y. and M. Cook, Numerical studies of displacement natural ventilation in multi-storey buildings connected to an atrium. Building Services Engineering Research and Technology, 2007. 28(3): p. 207-222.

41. Acred, A. and G.R. Hunt, Stack ventilation in multi-storey atrium buildings: A dimensionless design approach. Building and Environment, 2014. 72: p. 44-52.

42. Aldawoud, A., The Influence of the Atrium Geometry on the Building Energy Performance. Energy and Buildings, 2012. 57 p. 1-5.

43. Wang, F. and Abd Halid Abdullah, Investigating thermal conditions in a tropic atrium employing CFD and DTM techniques. International Journal of Low-Carbon Technologies 2011. 6: p. 171186.

44. Hussain, S. and P.H. Oosthuizen, Numerical investigations of buoyancy-driven natural ventilation in a simple atrium building and its effect on the thermal comfort conditions. Applied Thermal Engineering, 2012. 40: p. 358-372.

45. Moosavi, L., N. Mahyuddin, and N. Ab Ghafar, A comparison between atrium and courtyard cooling efficiency in hot tropical climate, implementing different passive cooling strategies. Journal of Renewable and Sustainable Energy, 2015. 7(4): p. 043108.
46. Mouriki, E., Solar-assisted hybrid ventilation in an institutional building. 2009, Concordia University (Canada): Canada. p. 174.

47. Lynch, P. and G. Hunt, The night purging of a two-storey atrium building. Building and environment, 2011. 46(1): p. 144-155.

48. Gan, G., Simulation of buoyancy-driven natural ventilation of buildings--Impact of computational domain. Energy and Buildings, 2010. 42(8): p. 1290-1300.

49. Mouriki, E., et al. Full-scale study of an atrium integrated with a hybrid ventilation system. in Proceedings of the $3 \mathrm{rd}$ Canadian Solar Buildings Conference, Fredericton, Canada. 2008.

50. Horan, J.M. and D.P. Finn, Sensitivity of air change rates in a naturally ventilated atrium space subject to variations in external wind speed and direction. Energy and Buildings, 2008. 40(8): p. 1577-1585.

51. Li, N.-p., et al., Effect of atrium configuration characteristic on buoyancy-driven ventilation of high-rise residential buildings. Journal of Guangzhou University (Natural Science Edition), 2010. 3: p. 015.

52. Hussain, S. and P.H. Oosthuizen, Validation of numerical modeling of conditions in an atrium space with a hybrid ventilation system. Building and Environment, 2012(52): p. 152-161.

53. Alexander, D., H. Jenkins, and P. Jones. $A$ comparison of wind tunnel and CFD methods applied to natural ventilation design. in Proceedings of Building Simulation. 1997.

54. Gan, G., Simulation of buoyancy-driven natural ventilation of buildings-Impact of computational domain. Energy and Buildings, 2010. 42(8): p. 1290-1300.

55. Gao, J., et al., Calculation of natural ventilation in large enclosures. Indoor and Built Environment, 2007. 16(4): p. 292-301.

56. Özgür Göçer1 Aslıhan Tavil2, E.Ö., SIMULATION MODEL FOR ENERGY PERFORMANCE AND USER COMFORT EVALUATION OF ATRIUM BUILDINGS, in Second National IBPSA-USA Conference 2006: Cambridge, MA p. 17-24.

57. Kim, K.-S., Development of daylighting prediction algorithms for atrium design. 1987, Texas A and M Univ., College Station (USA).

58. Navvab, M., Outdoors Indoors Lighting Design and Application, 1990. p6: p. 24-31.

59. Tan, G., Study of natural ventilation design by integrating the multi-zone model with CFD simulation. 2005, Massachusetts Institute of Technology: United States -- Massachusetts.

60. Wang, L. and Q. Chen, Theoretical and numerical studies of coupling multizone and CFD models for building air distribution simulations. Indoor Air, 2007. 17(5): p. 348-361. 